\title{
The Development and Review of Heterogeneous R\&D Cooperation, Enterprises Patent Quality and Internal/External Situational Factors*
}

\author{
Rongjian $\mathrm{Yu}$ \\ School of Business Administration \\ Zhejiang Gongshang University \\ Hangzhou, China
}

\author{
Jiami Zheng \\ School of Business Administration \\ Zhejiang Gongshang University \\ Hangzhou, China
}

\begin{abstract}
In this paper, from a new perspective of the heterogeneity of enterprise $R \& D$ cooperation, based on resources complementary theory and the theory of competition and cooperation, reviews and summarizes the current researches on the relationship between heterogeneous $R \& D$ cooperation and patent quality, as well as reviews and summarizes the research on the influence of external situational factors intellectual property protection and internal situational factors' absorptive capacity on the quality of heterogeneous $R \& D$ cooperation and patent. Finally, this paper summarizes the future research direction and emphasis.
\end{abstract}

Keywords-heterogeneous $R \& D$ cooperation; patent quality; intellectual property protection; absorptive capacity

\section{INTRODUCTION}

A. From "Quantity Pushing Type" to "Quality Climbing Type": the Paradigm Transformation of Knowledge Creation of Chinese Enterprises

In the era of economic globalization, with the rapid development of science and technology, enterprises urgently need to obtain market advantages through technological competition. As an important expression of intellectual property, patent is an important strategic point that enterprises must grasp. Therefore, enterprises pay more attention to the protection of patent rights, and patent $R \& D$ strategy is gradually promoted from "quantity promotion" to "quality promotion". Fierce competition makes enterprises realize that although the number of patents is important, the quality of patents is more important [28]. High-quality patents help enterprises develop products with high value, seize market share and obtain benefit guarantee. At the same time, highquality patents help enterprises reduce or avoid patent litigation disputes, provide legal protection for the mass production and sales of commercial products, enable enterprises to win the market reputation, and save a lot of costs for enterprises. At the same time, enterprises can make R\&D direction and strategic arrangement according to high-quality patents, identify competitors and their key profitable technologies, and win

*Project: This research was substantially supported by research grants from Key Projects of Philosophy and Social Science Planning in Zhejiang Province (Project Number: 16NDJC029Z) and National Natural Science Foundation of China (71773115). competitive advantages [39]. Therefore, it is particularly important to study the impact of heterogeneous $R \& D$ cooperation on patent quality and the impact of patent quality on the process of enterprises choosing partners for $R \& D$.

\section{B. From Closed Innovation to Open Innovation: a New Path of Innovation-driven Development}

Although many enterprises, such as Huawei and Geely Company, have successfully acquired innovation capabilities through open innovation, gained market advantages and profits from cooperative innovation, they are still many enterprises hesitant when facing the choice of $R \& D$ partners or fail to achieve expected results even if they carry out open innovation. Although the role of open innovation has been widely recognized and accepted, there is still a lack of clear strategic guidance and relevant experience accumulation in practice, the most prominent problem is the choice of R\&D partners [40]. Different types of organizations have different technology and knowledge structures. Universities are knowledge-oriented, while enterprises are technology-oriented. Differences in partners bring more uncertainties to enterprises' R\&D cooperation and innovation [25]. What is the relationship between partner difference and enterprise innovation capability and how enterprises should choose suitable R\&D partners has become an urgent problem in theory and enterprise practice. The research on the relationship between the organizational difference of partnership and patent quality can provide important decision-making basis for enterprises to choose partners of different organizational types in the practice of heterogeneous cooperative $R \& D$, and open up new paths for enterprises to innovate and develop.

\section{Cooperative $R \& D$ Seeks to Improve the Quality of Knowledge Innovation, and the Enterprise Faces Multiple Decision-making Difficulties}

In practice, due to the high risk, complexity and uncertainty of the innovation process itself [48], most enterprises are still follow the traditional pattern of innovation-the idea that innovation is the enterprise's own internal things, enterprises should rely on their ability to innovate, and to gain competitive advantage, enterprise is not willing to take risks in uncertain environment for innovation, and the result is that enterprise's 
innovation and innovation efficiency is much lower than expected, lead to enterprise investment without reward, thereby inhibition of enterprise innovation. In order to realize the further improvement of innovation ability and innovation performance, the important role of innovation environment cannot be ignored. Corresponding effective measures should be taken according to the actual situation to adapt to the innovation environment and improve the innovation ability [37]. So the enterprise in the process of $R \& D$ cooperation promote enterprise's patent quality really affected by what kind of situation, How to avoid the high risk, complexity and uncertainty of enterprise innovation process, and help enterprises to identify risks in $R \& D$ cooperation and the environment and encourage enterprises to R\&D of more effective cooperation, has become a problem in today's enterprises pay close attention to.

\section{RESEARCH TRENDS AND COMMENTS}

\section{A. Definition of Patent Quality and Development of Its Measurement Methods}

At present, it is difficult to define the patent quality, and there is no uniform definition for the research of domestic and foreign scholars. In summary, domestic and foreign researches have similarity evaluation angles based on different subjects' patent quality, one is based on the patent quality of examiners, the other is based on the patent quality of users. Based on the examiners' patent quality, the patent application is evaluated from the perspective of whether it conforms to the standard stipulated by law, and the quality of the patent is guaranteed through the strict patent examination system. Foreign scholar Wagner (2009) believes that patent quality is used to measure whether the authorized patent meets the criteria of patentability, especially the sufficient description of innovation, novelty and practicability. Song Hefa (2010) believes that the quality of a patent is a patent with high technical level, good writing, and can withstand review, invalidation and litigation procedures with greater market value. Thomas (2002) holds that highquality patents refer to valid patents that can be enforced by the court and can stand up to challenges in the case of patent litigation, and can be used as reliable tools for technology transfer. The technical quality of patent refers to the importance and advancement of the patented technology itself. Wan Xiaoli (2009) defined patent quality as: the importance of patented technology to users' competitiveness. The more advanced a technology is, the more important it is to users' competitiveness, and the higher its patent quality. The economic quality of patent refers to the market application value and economic prospect of the patented technology. Hall and Harhof (2004) believe that high-quality patents are patents that can commercialize valuable inventions. The ultimate purpose of enterprise patent quality measurement is to guide enterprises to know and improve their innovation ability.

Trajtenberg (1990) first proposed using the number of patent citations to evaluate the quality of patents. In China, since Gao Shanxing and Guo Huatao (2002) first used the patent maintenance rate evaluation, Zhu Xuezhong, Wan Xiaoli, and other scholars have conducted a series of scientific studies on the patent quality measurement indicators, and then the empirical research developed together with related indicators and indicator system research, promoting the continuous deepening of this research field. Subsequently, more and more scholars, such as STERZI (2013), Bian Yali (2013), Hu Die (2015) and Li Qiang (2016), adopted patent citation in their researches to study the quality of enterprise patents. It can be seen that this measurement method is relatively mature at present. Although there are many ways to evaluate the quality of patents, many scholars believe that patent citation is an effective way to measure the quality of patents by the number of citations.

\section{B. Research Results on the Relationship Between Heterogeneous R\&D Cooperation and Patent Quality Based on Multiple Theories}

Heterogeneous R\&D cooperation refers to the degree of differentiation and diversification of cooperative objects in the process of $R \& D$ cooperation. In the process of enterprise innovation, the most direct face is the external partner of different types of organizations, the classification of partners is a hot issue in research. More scholars in different ways to classify corporate partner organization heterogeneity, such as Nieto\&Santamaria (2007) divided external heterogeneous partners into four categories: customers, supply chain cooperation, competitors' cooperation and research institutions in the process of studying the impact of cooperative network heterogeneity on product innovation, and Tijssen (1998) divided the organizational heterogeneity of partners into public organizations and private organizations according to the purpose of organizational operation. The research results on the relationship between heterogeneous $R \& D$ cooperation and patent quality are as follows:

Based on relevant researches of resource-based theory, some scholars believe that the essence of heterogeneous R\&D cooperation is to obtain heterogeneous resources from the outside. Competitive enterprises, universities and research institutions, as the source and growth point of leading technologies, are an effective way for enterprises to acquire external technical capabilities [7]. Industry-university-research cooperation can make full use of this approach to enhance enterprise innovation performance and innovation ability. Therefore, for an enterprise, the diversity of cooperation types and cooperation scope of its partners will have a positive impact on its internal technology innovation ability [43]. For enterprises, the diversity of $R \& D$ partners can help them acquire more heterogeneous resources and improve their innovation ability [13]

Based on relevant researches on the resource complementarity theory, some scholars believe that the fundamental purpose of enterprises' heterogeneous R\&D cooperation is to obtain complementary resources [46], which will have a positive impact on the quality of patents. Due to the big difference in technical information between enterprises and universities, the purpose of patent production is different [26]. Compared with cooperation with enterprises, the complementary resources obtained by school-enterprise cooperation will be relatively reduced, and the decoupling of scientific research and practical application will make a large number of scientific research achievements produced by 
research institutions often remain at the theoretical level [44]. The realization of patent value depends on the cooperation of commercial complementary assets, and the cooperation with universities will lead to the reduction of commercial complementary assets obtained by enterprises [46], so the cooperation between enterprises is more conducive to improving the quality of patents.

The research based on the knowledge-based theory points out that enterprises choose to cooperate with colleges and universities to obtain more heterogeneous knowledge, which is conducive to the fundamental innovation of enterprises. Therefore, the cooperation between enterprises and universities can improve the quality of patents. Working with an organization helps the company acquire information, knowledge about potential partners and coordinate transactions between two or more parties [1]. While the cooperation among enterprises is becoming more competitive and protective, actions will be taken in the process of cooperation, which will hinder knowledge or information exchange between partners. Even partner companies may try to lure outstanding scientists or researchers of other partner companies, resulting in serious leakage of core knowledge of the cooperative company [19], school-enterprise cooperation is more conducive to improving the quality of enterprise patents

In summary, most of the research conclusions about the role of heterogeneity in $\mathrm{R} \& \mathrm{D}$ tend to have a positive impact on the quality of patents. However, when it comes to the selection of $R \& D$ partners, there are some differences in the research conclusions on the influence of competitive cooperation and non-competitive cooperation on patent quality. Some scholars believe that competitive $\mathrm{R} \& \mathrm{D}$ cooperation between enterprises is more conducive to improving the quality of enterprises' patents, while others believe that non-competitive R\&D cooperation between enterprises and universities is more conducive to improving the quality of patents. This has a lot to do with the different situational factors in which the enterprise is situated, for example, the intellectual property protection intensity [16], environmental dynamics [24], and government subsidies [11] of the external environment; and the absorption capacity [21], exploration and utilization learning [23], financing constraints [10] of internal environment. However, there is a lack of research on the impact of situational factors on the type of joint R\&D cooperation on patent quality, which is the focus of future research. The existing literature mainly compares the cooperation between enterprises and the impact of the cooperation between enterprises and universities and scientific research institutions on the quality of patents, but lacks a comparative study on the effectiveness of the cooperation between enterprises and domestic and foreign enterprises, universities and scientific research institutions.

Different conclusions on the influence of intellectual property protection level on enterprise $R \& D$ innovation.

\section{Different Conclusions on the Influence of Intellectual Property Protection Level on Enterprise R\&D Innovation}

Intellectual property protection level is a part of our country intellectual property strategy, intellectual property rights strategy is the creation, utilization and protection of intellectual property rights, management, personnel training, cultural construction as the content, pay attention to the level of intellectual property rights (quality) and ownership (quantity) coordination, promote the development of social science and technology, economy, culture of total strategy. Intellectual property creation mainly includes various intellectual property output, among which patent output is the most important part [36]. Therefore, the level of intellectual property protection, as an external situational factor of an enterprise, is closely related to the quality of its patents.

Intellectual property protection can promote and stimulate technological innovation. Intellectual property protection is considered a determinant of corporate investment in $R \& D$. Government intervention in the market through the implementation of intellectual property protection system, its basic aim is to provide the innovator monopoly (including time and range), protect it from imitators of competition, the $R \& D$ investment of enterprises can get more market share through monopoly advantage [41] and expected income [34], because only in this way can enterprises be willing to cooperate more and invest more $R \& D$ capital. There is a positive correlation between a country's knowledge protection mechanism and $R \& D$ investment density. The stronger the legal framework for intellectual property protection is, the more conducive it will be to stimulate the knowledge stock for technological innovation, encourage enterprises to carry out $\mathrm{R} \& \mathrm{D}$ cooperation and innovation, and create more efficient knowledge [4, 38].

The protection of intellectual property rights has a negative impact on technological innovation. It's necessary to look at the impact of intellectual property rights on technological innovation dialectically [5]. As a kind of technological innovation, patent quality will also be negatively affected by the level of intellectual property protection in the process of cooperative innovation. Due to the cooperative innovation is the enterprise process from partners to seek knowledge and ability, at the same time, facing its own key exposure risk at the core of knowledge, core resources, in turn, each cooperative members are reluctant to share with others, and lead to cooperation success rate decrease, so the intellectual property risk has become the first of the three risks of enterprise cooperative innovation [47]. Besides, the degree of protection of intellectual property rights is inconsistent and has great limitations in the technological innovation activities of enterprises of various types and sizes, which is determined by the reality [3]. The rapid development of science and technology makes it difficult to define the scope of intellectual property protection [42]. The cycle of new technology upgrading is getting shorter and shorter, and many technologies are often combined together, and the scope of definition is getting more and more complex. Sometimes it involves multiple laws, such as patent law and trademark copyright law, which will lead enterprises to seek other ways to seek benefits instead of focusing on improving enterprise innovation performance through patent R\&D. 
D. Based on Multiple Perspectives Research the Influence of Absorptive Capacity on the Relationship Between Heterogeneous $R \& D$ Cooperation and Patent Quality

Enterprises face different external environments when cooperating with different types of partners in $R \& D$. The $R \& D$ investment of an enterprise can improve its "Ability to recognize, digest and utilize knowledge in the environment", which is the absorptive capacity [8]. The absorptive capacity is directly manifested as the perception of the external environment. With the change of the external environment, the organization can perceive the change, acquire, digest and absorb the external changes, and successfully commercialize them [45]. In the process of cooperation with different types of partners, due to the change of external environment, the existing knowledge in the environment will change, and the influence of absorptive capacity will also be highlighted.

Analysis of the mediating effect based on the mechanism of $R \& D$ cooperation process. The fundamental purpose of open innovation cooperation is to obtain heterogeneous resources. The acquisition of heterogeneous resources will affect the absorption capacity of enterprises [14]. On the one hand, the absorptive capacity of an enterprise depends on its existing resources and previous experience, while the acquisition of external heterogeneous resources will affect the previous experience, and having sufficient knowledge base can improve the absorptive capacity of an organization [9]. On the other hand, absorptive capacity is regarded as a dynamic process of knowledge screening, absorption, transformation and integration. The acquisition of external heterogeneous knowledge can promote and influence the formation and accumulation of this dynamic process of absorptive capacity. Heterogeneous knowledge acquired from external heterogeneous partners can promote the dynamic improvement of the overall absorptive capacity of an organization [6].

An analysis of the regulatory effect is from the perspective of internal situation. Absorptive capacity emphasizes the cognition, mastery and application of external innovation opportunities. The stronger the absorptive capacity of an enterprise, the stronger its ability to grasp the operation of the external environment, and the more opportunities it has to introduce the spillover knowledge of partners and competitors into the enterprise [18]. When there is a lack of absorptive capacity, it is difficult for enterprises to acquire, absorb and utilize new external knowledge, which reduces the amount and creativity of using new knowledge in R\&D cooperation [30], thus resulting in low improvement of patent quality of enterprises

\section{CONCLUSION}

\section{A. Summary and Prospect}

To sum up, existing researches on the influence of heterogeneous $R \& D$ cooperation on patent quality include the following aspects: First, most scholars believe that heterogeneous R\&D cooperation will improve the quality of enterprises' patents, but relevant empirical studies are very scarce. Second, there are differences in comparative studies on the impact of inter-enterprise cooperation and school-enterprise cooperation on patent quality: some scholars believe that interenterprise cooperation is more conducive to improving the quality of enterprise patents; some scholars also believe that school-enterprise cooperation is more conducive to improving the quality of patents. Third, the dialectical influence of the level of intellectual property protection on the improvement of enterprises' own innovation ability: Some scholars believe that the improvement of knowledge protection level can protect innovation providers, make enterprises more comfortable to invest in $R \& D$, and improve the quality of patents; Some scholars also believe that the complex environment makes the protection of intellectual property very limited and inhibits enterprises from further investing in patent research and development. However, there is still a lack of research on the influence of the level of intellectual property protection on the relationship between cooperative $\mathrm{R} \& \mathrm{D}$ and patent quality. Fourth, influence mechanism of absorptive capacity based on different perspectives: Some scholars studied the intermediary role of absorptive capacity in the relationship between enterprise $R \& D$ and innovation performance based on the process mechanism of enterprise cooperative R\&D; Some scholars also studied its regulating effect on heterogeneous $\mathrm{R} \& \mathrm{D}$ cooperation and enterprise innovation performance from the perspective of situational factors. But such research is still lacking.

Therefore, the following conclusions can be drawn by summarizing the deficiencies of current studies and future studies direction: First, the influence of enterprise heterogeneous $\mathrm{R} \& \mathrm{D}$ cooperation on patent quality is still controversial. The influence of heterogeneous R\&D cooperation on enterprise patent quality can be further studied and the dispute content can be more clearly defined; second, there are different conclusions about the effect of the level of intellectual property protection on the relationship between heterogeneous R\&D cooperation and patent quality. Future studies can study the specific impact of the level of intellectual property protection on the relationship between heterogeneous R\&D cooperation and patent quality from the perspective of external contextual influencing factors; third, in terms of absorptive capacity, many studies focus on the impact of absorptive capacity on the innovation ability of enterprises, while studies based on the perspective of internal situational factors, research the impact of absorptive capacity on the relationship between heterogeneous $\mathrm{R} \& \mathrm{D}$ cooperation and patent quality of enterprises can still be carried out.

\section{B. Deficiencies and Future Directions}

This paper studies the regulating effect of external intellectual property protection and internal absorption capacity on the relationship between enterprise heterogeneity R\&D and patent quality. But the internal and external situational factors that influence the relationship between heterogeneity $R \& D$ cooperation and patent quality also include environmental dynamics, binary learning and other factors. 


\section{REFERENCES}

[1] Benjamin Weber, Sven Heidenreich. When and with whom to cooperate? Investigating effects of cooperation stage and type on innovation capabilities and success. Long Range Planning. 51(2018): 334-350

[2] Bian Yali. The Influence of Science Citation on the Firm's Patent Quality-Nanomaterial Industry as an Example. Journal Of Intelligence. 32.1(2013): 50-54

[3] Cai Xiang. Intellectual property incentives for technological innovation. Enterprise Economy. 1(2003): 67-68

[4] Cai Zhong-hua, An Ting-ting, Hou Ao-yu. The Robust Research on Determinants of R\&D Investmen - The Empirical Research Based on Provincial Panel Data. Soft Science. 2014,28(11): 119-122.

[5] Cao Yong, Hu Huan-huan. Analyzing the influence of intellectual property rights on the technological innovation dialectically: literatures review. Studies in Science of Science. 26.2(2009): 588-593

[6] Cassiman B,Veugelers R. In search of complementarities ininnovation strategy:Internal R\&D and external knowledge acquisition. Management Science. 52.1 (2006): 68-83

[7] Chen Yu-fen, Chen Ji. A study on the mechanism of open innovation promoting innovative performance. Science Research Management. 30.4(2009): $1-10$

[8] Cohen W. M. and Levinthal D.A. A.nthal. Innovation and learning: The two faces of R\&D Economic Journal. 99(1989): 569-596.

[9] Cohen W. M. and Levinthal D.A.. Absorptive Capacity: A New Perspective on Learning and Innovation. Administrative Science Quarterly. 35(1990): 128-152.

[10] David Diwei Lv, Ping Zeng, Hailin Lan. Co-patent, financing constraints, and innovation in SMEs: An empirical analysis using market value pane data of listed firms. Journal of Engineering and Technology Management. 48(2018): 15-27

[11] Florian Szücs. Research subsidies, industry-university cooperation and innovation. Research Policy. 47(2018): 1256-1266

[12] Gao Shan-xing, Guo Hua-tao. Estimates and Analyses of the Value of Patent Rights in China. Journal of Industrial Engineering Engineering Management. 2002(03): 66-68

[13] Geert Duysters and Boris Lokshin. Determinants of Alliance Portfolio Complexity and Its Effect on Innovative Performance of Companies. Journal of Product Innovation Management. 28(2011): 570-585

[14] Guo Wei. An empirical study of the influence of innovation openness to innovation performance of enterprises. Science Research Management. 2016,(10): 43-50.

[15] Hall B.H and Harhoff D. Post-grant reviews in the US patent System: Design Choice and Expected Impact. Berkeley Technology Law Journal. 19.3(2004): 989-1015.

[16] Henry R. Hertzfeld, Albert N. Link, Nicholas S. Vonortas. Intellectual property protection mechanisms in research partnerships. Research Policy. 35 (2006): 825-838.

[17] Hu Die, Wang Yuandi. On the Comprehensive Index for Firm's Paten Quality Evaluation and Its Application to Chinese GEM Enterprises. Journal Of Intelligence. 1 (2015): 77-82

[18] Jian Zhao-quan, Wu Long-zeng, Huang Jing. The impact of absorptive capability, knowledge integration on the organizational innovation and organizational performance. Science Research Management. 29.1(2008): $80-96$

[19] Kuo-Feng Huang, Chwo-Ming Joseph Yu. The effect of competitive and non-competitive R\&D collaboration on firm innovation. The Journal of Technology Transfer. 36 (2011): 383-403

[20] Li Qiang, Gu Xin, Hu Die. An Empirical Research on the Relationship between Patent Count, Quality and Firm Performance Based on Chinese GEM Enterprises. Science and Technology Management Research. 4(2016): 157-161

[21] M. Luisa Flor, Sarah Y. Cooper, María J. Oltra. External knowledge search, absorptive capacity and radical innovation in high-technology firms. European Management Journal. 36(2018): 183-194

[22] Nieto M. J., Santamria L. The inportance of diverse collaborative networks for novelty of product innovation. Technovation. 27.6(2007): 367-377
[23] Pengfei Wang, Vareska Van De Vrande, Justin J.P. Jansen. Balancing exploration and exploitation in inventions:Quality of inventions an team composition. Research Policy. 46(2017): 1836-1850

[24] Qian Yang, Xiande Zhao. Are logistics outsourcing partners more integrated in a more volatile environment? International Journal of Production Economics. 171 (2016): 211-220

[25] Ruan Xian-jing. Research on the Relationship between Partners and Innovation Performance under the Background of R\&D Organization Strategy. Journal of Technical Economics \& Management. 11(2018) $37-41$

[26] S.X. Zeng, X.M. Xie, C.M.Tam. Relationship between cooperation networks and innovation performance of SMEs. Technovation. 30(2010): 181-194.

[27] Song He-fa, Mu Rong-ping, Chen Fang. Study on the Patent Quality and It's Measurement Index System. Science of Science and Management of S.\&T. 2010,31(4): 21-27.

[28] Stefano Comino, Clar Graziano. How many patents does it take to signal innovation quality?. International Journal of Industrial Organization. 43(2015): 66-79

[29] STERZI V. Patent quality and ownership: An analysis of UK faculty patenting. Research Policy. 42.2 (2013): 564-576

[30] Su Zhong-feng, Wang Hai-rong, Zhang Wen-hon. Synergizing independent and cooperative R\&D activities: The effect of absorptive capacity. Science Research Management. 37.11(2016): 11-17

[31] Thomas J. The Responsibility of the rule maker: Comparative Approaches to patent administration reform. Berkeley Tech. L.J 17(2002): 728-761

[32] Tijssen R.J.W. Quantitative assessment of large heterogeneous R\&D networks: the case of process engineering in the Netherlands. Research policy. 26.7(1998): 791-809

[33] Trajtenberg M. A Penny for Your Quotes: Patent Citations and the Value of Innovation[J]. Rand Journal of Economics. 21.1(1990): 172181.

[34] Varsakelis N C. The impact of patent protection, economy openness and national culture on R\&D investment: Across-country empirical investigation. Research Policy. 30.7(2001): 1059-1068.

[35] Wagner R P. Understanding Patent Quality Mechanisms. University of Pennsylvania Law Review. 157.6(2009): 2135-2173.

[36] Wan Xiao-li. Patent quality index research. Wuhan: Huazhong university of science and technology. 2009.

[37] Wang Yu-rong, Shi Ping. The Mechanism and Countermeasures of Innovation Environment for Innovation and Innovation Performance. Scientific Management Research. 33.5(2015): 17-20

[38] Wu Y, Popp D, Bretschneider S. The effects of innovation policies on business R\&D: Across -national empirical study. Economics of Innovation and New Technology. 16.4(2007): 237-253.

[39] Xu Bo-tong. Quality or Quantity - Corporate Technology Innovation and Business Performance. Operations Research and Management Science. 27.11(2018): 193-199

[40] Xu Yang-yang. Study of Enterprise's Selection of Cooperative Partner Based on Network's Perspective. Science Technology and Industry. 11(2016): 126-131

[41] Yang L, Maskus K E. Intellectual property rights, technology transfer and exports in developing countries. Journal of Development Economics. 90.2(2009): 231-236.

[42] Yao Zhen. Problems and countermeasures of intellectual property system in the era of intellectual economy. Journal of Heilongjiang administrative cadre institute of politics and law. 2(2002): 64-66

[43] Yuandi Wang and Jason Li-Ying. Licensing Foreign Technology and the Moderating Role of Local R\&D Collaboration:Extending the Relationa View. Journal of Product Innovation Management. 32.6(2015): $997-$ 1013

[44] Zhang Gu-peng, Chen Xiang-dong. A Comparison of Patent Values between Corporations and Research Institutes based on Patent Renewal Period. China Economic Quarterly. 2012, 11(4): 1403-1425

[45] Zhang Jie, Qi An-bang, Xiong Qin-qin. The Antecedents, Absorptive Capability and Innovation Performance: Empirical Research on the 
Mediating Effects of Absorptive Capability. Science of Science and Management of S.\&T. 33.05(2012): 29-37.

[46] Zhang Jun-rong an open innovation improve the quality of patents? Science Research Management. 38.11(2017): 104-109.

[47] Zhang Ke-ying, Huang Rui-hua, Wang Zhong. A CooperativeInnovation-Based Analysis of the Factors That Influence Intellectual Property Risk. The Management and Policies of Sciences and Technologies. 18.5(2006): 9-14.

[48] Zhao Xin-hua.The Study on Scientific and Technological Innovation Environment and Evaluation Index System. Journal of Shanghai Economic Management College. 11.4(2013): 9-14. 